\title{
A ARTE DECORATIVA BRASILEIRA INSPIRADA NA CERÂMICA MARAJOARA
}

\author{
Patrícia Bueno Godoy ${ }^{1}$
}

\section{Resumo}

A presente comunicação tem por objetivo destacar uma das mais férteis fontes inspiradoras para a arte decorativa ao longo da primeira metade do século XX: a cerâmica da cultura marajoara. Seus padrões decorativos inspiraram projetos para a arte decorativa, ornamentações arquitetônicas e ilustrações. Entretanto, estes não foram os únicos padrões pesquisados naquele período. Provenientes de outras culturas indígenas, também foram consultados pelos artistas. Para discorrer sobre o tema trataremos de uma breve análise do repertório ornamental do professor do curso de Pintura da Escola Profissional Masculina de Rio Claro-SP, Carlos Hadler (1885-1945), autor intitulado 88 motivos ornamentais marajoara s.d, provavelmente concebido no final da década de 1930.

Palavras-chave: Arte decorativa-Brasil, Cerâmica Marajoara, Carlos Hadler (1885-1945), Theodoro Braga (1872-1953).

A arte decorativa brasileira permaneceu quase que totalmente na obscuridade durante o século XX. Não fossem as esporádicas citações sobre sua produção, para a complementação de textos dedicados à história da pintura ou da arquitetura, não teríamos hoje sequer estudos que a contextualizasse, especialmente, no âmbito da arte moderna brasileira. Com o objetivo de ampliar a análise da sua contribuição, fixaremos no complexo universo da arte decorativa inspirada na cerâmica marajoara.

Seja no aspecto temático quanto no ineditismo das formas, a arte decorativa produzida nos primeiros anos do século XX ajudou a alterar a situação de colônia, caracterizada pela importação de modelos das mais diversas procedências. Artistas como Eliseu Visconti (1866-1944) e Theodoro Braga (1872-1953) lançaram nesses primeiros anos objetos e projetos em arte decorativa inspirados em elementos nacionais, com a finalidade de enraizar uma herança comum no cerne da arte brasileira. ${ }^{2}$ Essa espécie de construção de uma memória nacional da arte, causaria uma identificação capaz de afastar qualquer atitude estrangeira presente no cotidiano do povo brasileiro. É compreensível que tal atitude seja empreendida pelos profissionais ligados à arte decorativa, uma vez que suas composições invadiriam desde os redutos familiares mais humildes aos mais sofisticados.

O trabalho do artista-decorador é dividido em três momentos: a idéia ornamental, a composição e a aplicação ao objeto material. A idéia ornamental é gerada a partir do modelo que será interpretado. ${ }^{3}$ No caso de Theodoro Braga, os modelos a serem interpretados no repertório ornamental concebido pelo pintor em 1905, intitulado A planta brąileira (copiada do natural) e applicada á ornamentação ${ }^{4}$, são exclusivamente nacionais. Nele, o artista paraense utiliza os modelos da flora e fauna brasileiras e os padrões decorativos retirados da cerâmica produzida por culturas indígenas. Theodoro Braga dedicou sua vida à divulgação dessa pesquisa, conseqüentemente, influenciou artistas nos mais diversos recantos do país. Carlos Hadler (1885-1945) deixou-se influenciar pela proposta do pintor

\footnotetext{
${ }^{1}$ Doutorado em História (Política, Memória e Cidade), IFCH-UNICAMP, 2004, Mestrado em História (História da Arte e da Cultura), IFCH-UNICAMP, 1999.

2 Godoy, pp. 36-44.

${ }^{3}$ Gauthier, Capelle, c1920. p. I.

${ }^{4}$ Manuscrito, acervo da Biblioteca Mário de Andrade, São Paulo, SP.
} 
paraense em 1927. Como Professor do curso de Pintura da Escola Profissional da cidade de Rio Claro, SP, Hadler operou como difusor local do projeto de nacionalização da arte brasileira durante as décadas de 1920 e 1930. Significativo para o tema aqui proposto é o repertório ornamental inédito, realizado por Hadler na década de 1930, intitulado 88 motivos ornamentais marajoara ${ }^{5}$.

Natural de Belém-PA, Theodoro Braga desempenhou durante sua vida um trabalho plural, seja como historiador, artista-decorador ou pintor de história. Adentrou o século XX com um repertório ornamental que se afasta dos estilos históricos. Em A planta brazileira (copiada do natural) applicada a ornamentação - manuscrito pertencente ao acervo da Biblioteca Mário de Andrade, em São Paulo - Theodoro Braga utilizou, inicialmente, elementos da flora brasileira aplicados à ornamentação em suportes diversos. Anos mais tarde, realizou ornamentações com elementos da fauna brasileira, motivos decorativos da cerâmica da cultura marajoara, entre outros, retirados de ornamentos produzidos por índios habitantes das margens do Rio Negro [figura 1]. Das 42 ilustrações desse repertório, 10 teriam sido provavelmente executadas entre 1905 e 1914 e inseridas na seqüência numérica do repertório, inicialmente dedicado à flora brasileira. Em seu livro Artistas pintores no Brasil (1942), Theodoro Braga traz uma lista com suas obras publicadas e inéditas. Um desses itens vem assim denominado:

Obra de Nacionalização da Arte Brasileira

1.a Série - Arte Decorativa - Inspirada na Flora, na Fauna e nos Motivos de Cerâmica dos Indígenas Brasileiros (Adquirida pela Municipalidade de São Paulo) - 1905-1914.

Certamente, Theodoro Braga está aqui se referindo ao seu repertório ornamental, $A$ planta brąileira (copiada do natural) applicada a ornamentação [figura 2].

Nas décadas seguintes os padrões decorativos provindos das culturas indígenas brasileiras aparecerão na ilustração, na arte decorativa e na arquitetura. Essas incidências foram designadas pela historiografia como "arte marajoara", "estilo marajoara" e "marajoara déco", definições insatisfatórias pela restrição que estabelecem a uma produção tão sofisticada e variada realizada durante a primeira metade do século XX. Tal generalização deve-se à ampla recorrência dos artistas aos padrões da cerâmica marajoara desde o final do século XIX muito visada por comerciantes e colecionadores ${ }^{7}$ - produção de exuberante decoração realizada pelos habitantes da ilha de Marajó, no Pará.

Aqui optaremos pela definição "neomarajoara" para caracterizar uma produção variada, inspirada nos padrões ornamentais das culturas indígenas brasileiras, característica da primeira metade do século XX.

Os padrões ornamentais de culturas indígenas aparecem nas obras do caricaturista e ilustrador carioca J. Carlos (1884-1950), especialmente na década de 1920. Nesse período ele trabalhava para a revista Ilustração Brasileira executando seu design gráfico e ilustrações, muitas delas de páginas inteiras. J. Carlos recorreu com maior freqüência aos motivos da flora e fauna brasileiras para a execução de adornos, letras capitulares, vinhetas e logotipos. ${ }^{8}$ Utilizou também, em menor escala, mas não com menor qualidade, os padrões retirados de culturas indígenas. A página do editorial da revista Ilustração Brasileira, de dezembro de 1923, traz o logotipo da revista inserido sobre um fundo aparentemente de inspiração

\footnotetext{
${ }^{5}$ Obra pertencente a uma coleção particular, São Paulo, SP.

${ }^{6}$ Guia da Arquitetura Art Déco no Rio de Janeiro, 2000. p. 15; Bruandt, 1981. p. 81.

${ }^{7}$ Mostra do Redescobrimento: Arqueologia. 2000. p. 95

8 Sobral, pp. 124-159
} 
marajoara realizado em vermelho. Na ilustração para a capa da revista Fon-Fon, J. Carlos apresenta uma imagem essencialmente simétrica. $\mathrm{O}$ título da revista funde-se com a ilustração numa composição que traz uniformidade nas linhas e na aplicação das cores. No eixo central encontra-se a imagem de uma cerâmica de inspiração marajoara.

A artista Íris Pereira foi professora de estilização em um curso de arte e decorativa. Em seu "Vaso em forma de igaçaba", reproduzido pela revista Ilustração Brasileira, em outubro de 1935, é possível observar o desenvolvimento da ordem, da precisão e da clareza gráfica para essa composição, qualidades possíveis graças à utilização rigorosa da geometria. ${ }^{\text {? }}$

$\mathrm{Na}$ arquitetura, a sede do Instituto do Cacau em Salvador, BA, é um projeto do arquiteto belga Alexander Buddeus. A edificação realizada em 1933-1936 foi projetada para armazenar e escoar, com total eficiência, as sacas de cacau até o porto. ${ }^{10}$ Hoje, essa sofisticada construção abriga, desde 1994, o Museu do Cacau. Destaque para o hall de exposições totalmente ornamentado sob a inspiração da cerâmica marajoara. Os motivos são encontrados nas colunas, nos entalhes da mobília, nas vidraças e no trabalho em serralheria.

$\mathrm{Na}$ arquitetura a inspiração em padrões retirados das culturas indígenas esteve presente também em habitações particulares. A residência de Affonso Gomes Dias, construção de grandes dimensões, é um projeto de Eduardo Souto de Oliveira, dos anos de 1934-1935. Localizada em Botafogo, no Rio de Janeiro, tem como destaque os motivos decorativos na fachada inspirados na cerâmica marajoara. ${ }^{11}$

$\mathrm{Na}$ arte decorativa, Carlos Hadler desenvolveu junto aos alunos da Escola Profissional estilizações a partir da proposta difundida por Theodoro Braga. Também realizou uma produção particular, como a ornamentação para o "Carnaval Marajoara", realizado em 1938 no salão social do clube Ginástico, da cidade de Rio Claro.

Carlos Hadler destaca-se, sobretudo, pela concepção de um repertório ornamental de relevante qualidade. O texto introdutório, as legendas e as páginas ilustradas com tinta preta sobre papel, exprimem a intenção do seu autor em publicá-lo. Isso jamais ocorreu.

A década de 1930 demonstra um crescente interesse científico pela arqueologia brasileira. É o que revela a imensa quantidade de publicações sobre o assunto nesse período. Significativas são as duas edições de Introdução à arqueologia brasileira: etnografia e história, publicadas em 1934 e 1938 de autoria de Angyone Costa, naquela época, professor de Arqueologia brasileira no Museu Histórico Nacional.

O conhecimento obtido por Carlos Hadler sobre a produção ornamental dos índios brasileiros, certamente provinha de duas fontes: do contato íntimo com a coleção de artefatos indígenas de Gualter Martins, da cidade de Rio Claro, SP, e das inúmeras edições sobre a arqueologia brasileira. Estabeleciam-se assim, as condições necessárias para a descoberta estética de Carlos Hadler, que somadas aos propósitos divulgados por Theodoro Braga, possibilitou a execução dos 88 motivos ornamentais marajoara. É significativa a presença de várias ilustrações similares àquelas reproduzidas na obra de Angyone Costa, reproduções realizadas pelo pintor Fernando Martins, que as realizou a partir da observação direta dos artefatos ou das ilustrações de publicações do Museu Nacional e do Museu Emílio Goeldi. ${ }^{12}$

\footnotetext{
${ }^{9}$ Ilustração Brasileira, 1935, p. 18.

10 Segawa, 1999, pp. 68-69.

${ }^{11}$ Guia da Arquitetura Art Déco no Rio de Janeiro, 2000. p. 67.

12 Costa, 1938. p. 338.
} 
O repertório 88 motivos ornamentais marajoara é constituído por 5 páginas datilografadas e 29 pranchas, nas quais encerram os 88 motivos ornamentais, concebidos por meio da geometria. Não são apenas cópias dos padrões ornamentais indígenas, são interpretações do primitivo, sob a perspectiva do próprio artista.

No momento da estilização, o estudo da geometria é essencial para o artista. Esse procedimento causa adaptações para que sejam firmadas as continuidades necessárias para a aplicação ao objeto material. Os motivos utilizados com maior freqüência são aqueles geometrizantes e aparentemente abstratos. No entanto, é possível verificar, com menor freqüência a utilização de representações zoomórficas, como na figura $n^{\circ} 62$ da Tábua $n^{\circ}$ 20. Os motivos aparentemente abstratos da cerâmica da cultura marajoara, na verdade, possuem todos os requisitos necessários para a existência de uma linguagem visual iconográfica. Os desenhos estilizados ao extremo não podem ser reconhecidos imediatamente pelo espectador, mas que desempenhariam importante instrumento de afirmação étnica por estarem ligados ao repertório mítico do grupo. ${ }^{13}$

Após essa rápida visitação à produção neomarajoara é possível estabelecer algumas considerações indispensáveis para futuras indagações sobre o tema. No caso específico da utilização dos padrões ornamentais da cultura marajoara é preciso tecer análises mais cuidadosas. Em primeiro lugar, sua utilização não ocorre apenas nas décadas de 1920 e 1930, como geralmente se tem admitido. A arte decorativa já recorria a esse tema, pelo menos em 1914. Os projetos e obras não teriam sido todos realizados sob o olhar atento do artista sobre um original autenticamente marajoara. Ou, mais além, a partir do repertório de autoria de Carlos Hadler, é possível comprovar a utilização de artefatos arqueológicos das mais diversas procedências, já que naquele momento poucas instituições do país possuíam exemplares autenticamente marajoaras. Durante o traçado, o artistadecorador interpretava, fazia adaptações amparadas pelos princípios da geometria, não raramente "inventava" um motivo ornamental.

Acompanhando a trajetória de Carlos Hadler e do seu repertório ornamental, percebemos a complexidade do tema. É preciso reabilitar a produção ornamental brasileira. A partir de pesquisas sistemáticas sobre a arte decorativa é possível dimensionar sua real contribuição, especialmente para o estabelecimento da arte moderna brasileira.

\section{Bibliografia}

BRAGA, Theodoro. A planta brazileira (copiada do natural) applicada à ornamentação. Manuscrito com introdução de Manoel Campello. Belém, Pará, 1905. - Artistas pintores no Brasil. São Paulo: São Paulo Editora Limitada, 1942

BRUAND, Yves. Arquitetura contemporânea no Brasil. São Paulo: Editora Perspectiva, 1981. COSTA, Angyone. Introducão a arqueologia brasileira: etnografia e história. São Paulo: Companhia Editora Nacional, Rio-Recife-Porto Alegre, 1938. $2^{a}$ edição.

GAUTHIER, Joseph \& CAPELLE, Louis. Traité de composition decorative. Paris: Librairie Plon, (c 1920).

GODOY, Patrícia Bueno. Carlos Hadler: apóstolo de uma arte nacionalista. Campinas, SP, 2004. Tese (Doutorado) - Universidade Estadual de Campinas, Instituto de Filosofia e Ciências Humanas.

Guia da arquitetura Art Déco no Rio de Janeiro [organizador: Jorge Czajkowski]. Rio de Janeiro: Centro de Arquitetura e Urbanismo, 2000. (Guias da arquitetura do Rio de Janeiro).

Ilustraşão Brasileira. Ano 12, nº 6, outubro de 1935, p. 18.

13 Shaan, 1997. p. 150. 
Mostra do redescobrimento: arqueologia. Nelson Aguillar, organizador./Fundação Bienal de São Paulo. São Paulo: Associação Brasil 500 Anos Artes Visuais, 2000.

SEGAWA, Hugo. Arquitetura no Brasil 1900-1990. São Paulo: Editora da Universidade de São Paulo, 1999.

SCHAAN, Denise Pahl. A linguagem iconográfica da cerâmica Marajoara. Porto Alegre: Edipucrs, 1997. Dissertação de Mestrado. Pontifícia Universidade Católica do Rio Grande do Sul.

SOBRAL, Julieta Costa. "J. Carlos, designer", in: CARDOSO, Rafael. O design brasileiro antes do design: aspectos da história gráfica, 1870-1960. Organizador: Rafael Cardoso. São Paulo: Cosac Naify, 2005.

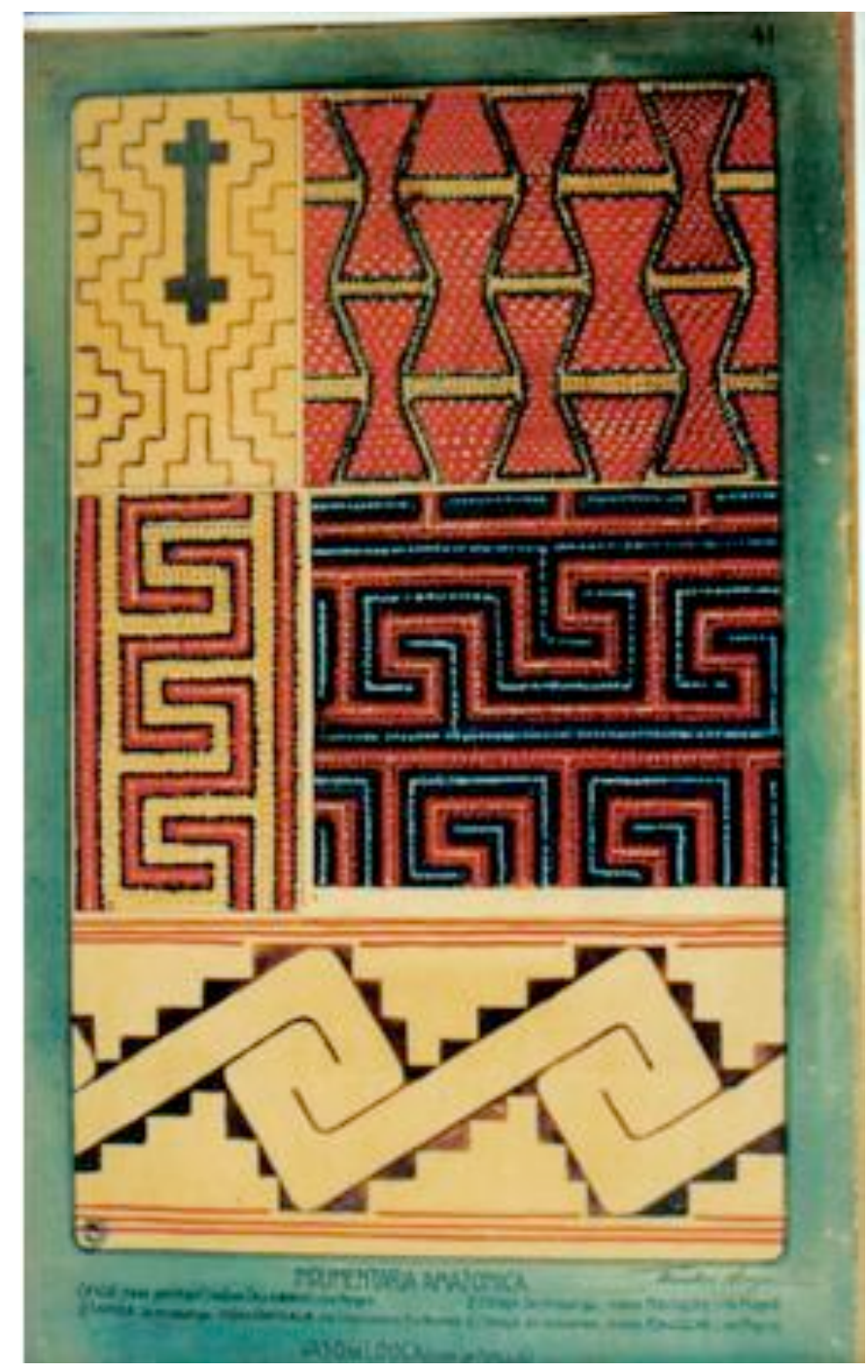

Figura 1

Theodoro Braga

A planta brazileira (copiada do natural) applicada a ornamentação (1905)

Fonte: Biblioteca Mário de Andrade, São Paulo-SP 


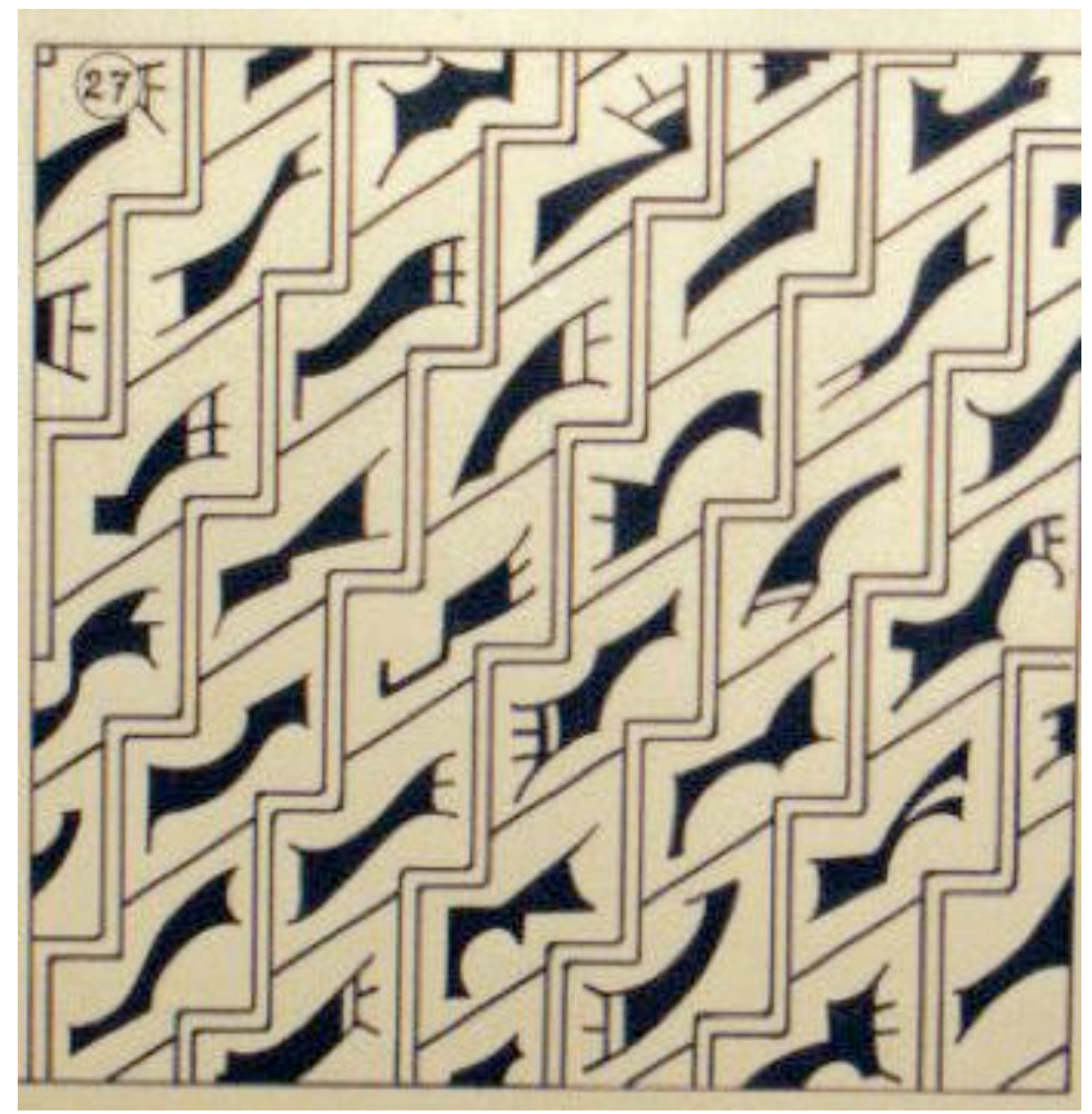

Figura 2

Carlos Hadler,

88 motivos ornamentais marajoara, s.d.

Tábua 9 - Figura 27

“Ornamento (pintado) de uma urna funerária" 